\title{
Therapeutic gene editing is here, can regulations keep up?
}

\author{
Soumya Kannan ${ }^{1,2 *}$ and Devora Najjar ${ }^{3,4}$ \\ Edited by Manraj S. Gill and Anthony Tabet
}

\section{HIGHLIGHTS}

- We are in a genetic revolution, with new gene editing technologies and applications being developed at a rapid pace.

- Genome editing is already being used in clinical settings, but technical challenges and ethical questions remain.

- Additional oversight is required for effective widespread implementation of genome editing therapies in a safe and ethical manner.

Genome editing and the technologies that enable it have sparked public discussions as investments in research and development continue to soar. Available gene editing modalities are enabling far-reaching applications beyond heritable genome modifications, ranging from novel therapeutics and cancer immunotherapies to engineered crops and livestock. However, many challenges, both practical and ethical, still exist before genome editing technologies can be implemented. Existing legal frameworks, both national and international, are racing to keep pace with the development of gene editing technologies. Updating regulations on gene editing can help provide a framework under which scientists and the public operate. Shaping and implementing proper regulations will require engagement from all impacted stakeholders. Here, we present a comprehensive review of the current scientific and regulatory landscape of this field of gene editing in order to stimulate necessary conversations regarding future regulations in the broader community.

$\mathrm{n}$ recent years, genome editing technology has come to the forefront of therapeutic biotechnology development and has already begun to revolutionize medicine. Since

\footnotetext{
${ }^{1}$ Department of Biological Engineering, Massachusetts Institute of Technology, Cambridge, MA

${ }^{2}$ Broad Institute of MIT and Harvard, Cambridge, MA

${ }^{3}$ MIT Media Lab, Massachusetts Institute of Technology, Cambridge, MA

${ }^{4}$ Wyss Institute for Biologically Inspired Engineering, Harvard University, Boston, MA

*Email: soumyak@mit.edu
}

The authors declare no conflict of interest.

(C) 2020 The Author(s)
CRISPR-based genome editing was first demonstrated in 2013 [1]-[4], there have been over a dozen clinical trials for CRISPR-enabled therapeutics, including treatments for blood disorders, cancers, and even childhood blindness $[5,6]$. However, the growing popularity of genome editing technologies has challenged the existing frameworks that regulate them [7]. Some countries have updated their regulatory systems in an attempt to assure the translation of research to a clinical setting, while others are lagging behind $[8,9]$. While international coordination is usually not sought for biomedical breakthroughs and their applications, the case of gene editing is an exception, as these technologies having the potential to alter the human species in ways that transcend borders.

The above mentioned clinical trials for CRISPR-based therapeutics involve editing somatic cells (cells that are not heritable) within a patient. Thus, while these somatic cell CRISPR therapy trials allow for treatment of the patient administered with the therapy, they do not provide a cure for future generations. Heritable genome editing occurs when edits are made to germline cells (cells that give rise to egg or sperm cells), creating the potential to pass the edits to all cells within an organism, as well as to propagate the edits to future generations. The possibility that CRISPR could be used for therapeutic germline editing creates ethical questions around who must be consulted before proceeding, because the results carry consequences for not only the patients, but for the entire species $[10,11]$.

As such, somatic and germline therapies are regulated differently, particularly at the experimental research stage. Due to the sensitive nature of human germline genome editing, which requires manipulating and growing human embryos, many countries either do not allow research or have strict regulations for early stage experimental research. Somatic editing therapies avoid these ethical issues inherent in germline editing therapies, so much of the regulation for somatic editing therapies lies in the safety of the therapy rather than the ethics.

However, in 2018, before ethical questions around germline editing could make significant progress, He Jiankui of the Southern University of Science and Technology in Shenzhen, China announced that he had used CRISPR-Cas9 
to edit the genomes of two human embryos [12]. The edit he attempted to introduce was to break the human CCR5 gene, which encodes a protein used by HIV during infection [13]. These embryos were implanted and carried to term, leading to the first babies born with heritable genome edits. The experiment was heavily criticized for its lack of transparency and its lack of clarity on whether the parents were properly informed of the risks $[14,15]$. It was also criticized for its lack of justification given the existence of other safe and approved preventative measures for HIV, and given the lack of understanding of the risks of knocking out this gene [16].

This event led to an outcry within the scientific community [17]. Many scientists reaffirmed the long-agreed upon stance that such heritable genome editing experiments are beyond the current ethical bounds of the use of genome editing technology $[18,19]$. Even so, this consensus has not necessarily stopped some scientists from continuing such controversial experiments, as proven by Russian scientist Denis Rebrikov, who also plans to edit human embryos, albeit with more transparency [20,21]. Rebrikov will target a gene implicated in congenital deafness and will delay embryo implantation until full regulatory approval is granted. While the differences are encouraging, Rebrikov's announcement brings the questions regarding heritable genome editing raised by He's experiments to the forefront once again [22].

In light of this experiment and subsequent announcements, earlier debates on genome editing ethics and calls for a global moratorium on heritable genome editing in humans have been reignited [23,24]. Responses from scientists and ethicists largely echo earlier sentiments on severely limiting this area of research and continuing a moratorium on its applications $[25,26]$. However, there is now added urgency for more concrete action and guidance from international bodies considering He's claim that he felt he was actually following the National Academy of Sciences guidelines when performing his experiment [27]

Here, in an effort to inform how future regulation may be shaped, we explore the most common genome editing technologies, their current applications, and the technical and regulatory challenges that lay ahead.

\section{Modalities of genome editing}

The quest to manipulate DNA has been ongoing since before the rules and structure of the genetic code were even discovered. Precise manipulation of a DNA sequence in a genome, however, is dependent upon developing a technology that can initially recognize a specific DNA sequence and subsequently change it. The process often begins by creating a double-stranded break in the genome with a DNA-cleaving enzyme (nuclease). Once there is a break, the cell has two pathways that can repair such breaks: non-homologous end joining (NHEJ) and homology directed repair (HDR) [28].

With NHEJ, the cell attempts to repair the break by joining the broken DNA together without any template. This typically leads to insertions or deletions of random DNA sequences at the break site, often resulting in gene inactivation. Researchers take advantage of this pathway to create gene knockouts, in which simply inactivating the gene is the desired outcome. HDR, however, is not random and is a more precise method of DNA repair used by the cell. In HDR, a DNA template in the cell that matches the area around the break site serves as a reference for repair $[1,3]$. By artificially providing such a DNA template to the cell, researchers can make use of of the cell's own HDR pathway to precisely introduce the researchers' desired DNA edits (insertions, deletions, or specific replacements) at the break site.

The possibility of precise editing of DNA through a targeted double stranded break within a cell first became a reality with I-Scel meganucleases naturally found in yeast, but the process was difficult and required the prior insertion of recognition sites for the meganuclease [29, 30]. More notable was the zinc finger nuclease (ZFN), which combines zinc fingers (proteins that can recognize specific DNA sequences via modular "fingers") and a Fokl nuclease. This combination creates a synthetic genome editing tool that is able to locate using the zinc finger component and cut precisely using the nuclease component at a desired DNA sequence [31,32]. Zinc finger nucleases were the first exploration of the principle that DNA-binding proteins could be constructed to specifically recognize an arbitrary sequence of interest, and they paved the way for further conceptual advances in development of genome editing technologies [33].

The next synthetic DNA editor developed was the transcription activator-like effector nuclease (TALEN) [34]. Similar to ZFNs, these synthetic nucleases were created by fusing a customizable DNA-binding array found in plant pathogens, called TAL effectors, to the Fokl nuclease [35]. The array has a decipherable "language" that allows it to be stitched together in order to target a specific DNA sequence of interest [36].

However, the most prominent and widespread tool now used for genome editing applications is CRISPR-Cas9. CRISPR (Clustered Regularly Interspaced Short Palindromic Repeats) systems naturally act as a bacterial and archaeal form of adaptive immunity against invading viruses [37]. When bacteria containing a CRISPR system survive a viral attack, they save a fragment, called a "spacer," of the viral DNA within their own genome [38]-[40]. These spacers were shown to be a kind of genetic memory of viruses that allow bacteria to quickly recall and mobilize a defense if attacked again in the future [41]. When a virus whose genome matches one of the saved spacer sequences invades the bacterial cell again, a CRISPR-associated (Cas) enzyme uses the spacer as a guide to find and cut the viral DNA specifically at this target sequence, thereby inactivating the virus [42].

After experimentally proving that only a single enzyme, Cas9, together with an RNA guide is needed in order to generate a protective response against a viral invader [43], the enzyme was reprogrammed simply by changing the spacer sequence and shown to effectively target and 
cut programmed sequences of DNA in both prokaryotic and eukaryotic organisms [1]-[4]. This development was a paradigm shift for genome editing. Not only is CRISPR-Cas9 a naturally-derived precise and programmable genome editing tool, but it is simpler and easier to use for genome targeting than both ZFNs and TALENs.

To use the CRISPR-Cas9 system, all a researcher needs is the Cas9 enzyme and an RNA guide to the DNA sequence they would like to target (with the only limitation in the DNA target sequence being the need for a Cas9-specific protospacer-adjacent motif (PAM), which is a DNA sequence needed for the Cas9 to bind to the DNA site). Due to the ease of design and implementation, this method of gene editing was quickly adopted and has become one of the most common methods of gene editing in both research and therapeutic applications today.

Since the first application of Cas9 for DNA modification in human cells, the CRISPR toolkit has rapidly expanded. Cas enzymes have been both discovered and engineered to have unique properties that can better aid researchers in their work. This includes CRISPR nucleases with alternate PAM requirements [44]-[48], alternate DNA modification methods [49,50], and even CRISPR-based methods of RNA targeting and editing [51,52], gene activation and repression $[53,54]$, and epigenetic modification [55]. These new enzymes continue to expand the possible targeting capabilities, making genome modification quicker and easier [56].

\section{Therapeutic genome editing}

Genome editing holds great promise for inventing a host of therapeutics that use both ex vivo (editing taking place outside of the body in a lab) and in vivo (editing taking place within the body) modalities to provide treatments $[5,58]$. In particular, monogenic diseases, or diseases that are caused by mutations in one specific gene, such as sickle cell disease and cystic fibrosis, are poised to benefit greatly from these advances.

Genome editing differs from gene therapy in that it aims to change the genome of the cell, whereas gene therapy is the term generally used to refer to the class of therapies that deliver a new copy of a healthy gene to a cell, leaving the cell's genome itself untouched. Moreover, cell therapies generally refer to the use of either ex vivo genome editing or ex vivo gene therapy prior to infusion of these modified cells into a patient. This means that cells are removed from a patient, modified, and then returned to the patient's body as a therapeutic.

When using gene editing, there needs to be a method by which the components are delivered to cells, either within the body or in a dish. This can be done through physical delivery, viral vectors, or nanoparticles [58,60]. Physical delivery methods are typically used for ex vivo cell editing, and involve electroporation or microinjection of DNA or RNA templates or the nucleases themselves into cells. Viral vectors can be used for both transient or stable expression of genes within cells, depending on the needs of the therapy. These

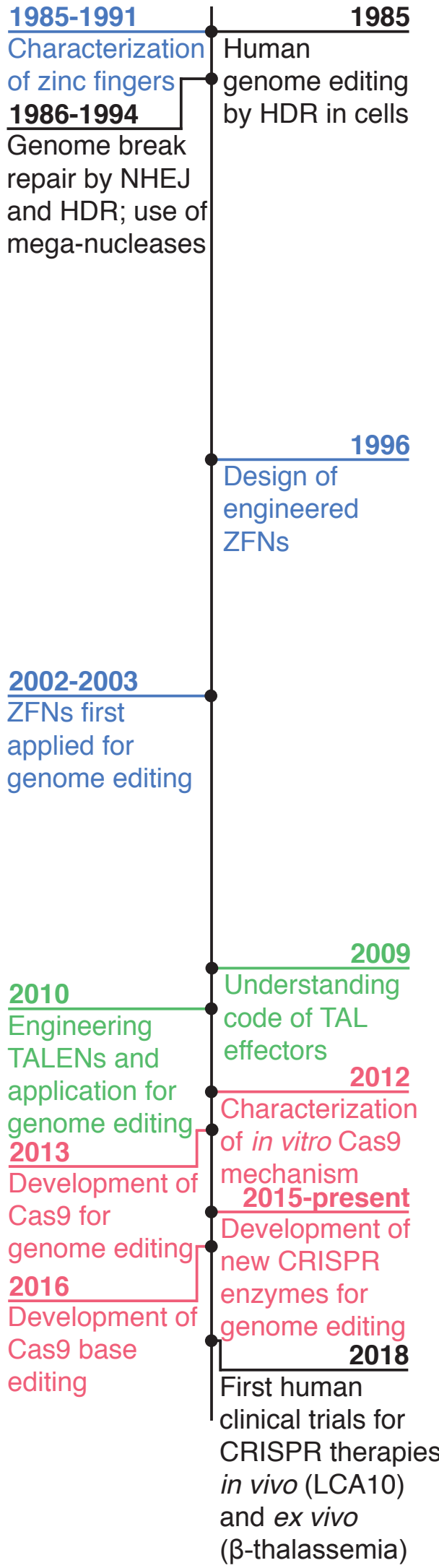

Figure 1: Timeline of genome editing technology development Adapted from [57]-[59]. 
vectors can be used both for ex vivo as well as in vivo delivery. Finally, alternative delivery methods such as liposomes and gold nanoparticles can be used in both in vivo and ex vivo therapies as well.

Current clinical trials are largely exploring use of ex vivo genome editing to develop cures mainly for monogenic diseases. For blood diseases that are caused by mutations in the beta globin gene, such as sickle cell anemia and beta thalassemia, for example, a patient's blood stem cells are extracted and edited to knock out expression of a repressor of fetal hemoglobin. This edit allows fetal hemoglobin to be expressed and compensate for the mutated beta globin protein [61]. Clinical trials are now underway for this therapy and thus far seem promising [62]. Most notably, March 2020 saw the first clinical trial of an in vivo CRISPR-Cas9 gene therapy, targeted to treat Leber's congenital amaurosis 10 (LCA10), the leading cause of childhood blindness for which there is currently no cure [63].

Such genome editing therapies can also be applied to disorders where the genetic cause is less straightforward than a single mutation somewhere in the sequence of a gene. For example, in mouse models of Huntington's disease, disruption of the aberrant expansion of repeating sequences in the gene encoding the huntingtin protein can lead to a decrease in the aggregation of the protein. Aggregation of the huntingtin protein caused by these expanded repeats is known to be one of the causes of the disease pathology [64]. This genome editing treatment thereby results in an increased lifespan of the mice in mouse models mimicking this disease [65]. Similarly, disruption of the PCSK9 gene can lead to reduced plasma levels of cholesterol in humanized mouse models of hypercholesterolemia [66].

Apart from making edits that directly impact disease-causing mutations in genes, it is possible to engineer cells to subsequently enact therapeutic functions. This is the approach taken in some immunotherapies, a form of therapy that aims to use a patient's own immune system to fight diseases such as cancer. Most notable in this space is KYMRIAH (Tisagenlecleucel), an FDA-approved treatment from Novartis, that is used for acute lymphoblastic leukemia. This involves harvesting the $T$ cells of a patient and engineering the genome of these immune cells ex vivo to introduce in them a protein that allows these modified $T$ cells (CAR-T cells), upon their reintroduction to the patient, to find and kill cancerous cells in the patient's blood $[67,68]$. Though KYMRIAH does not use CRISPR, CRISPR-based genome editing may make such treatments cheaper and easier to produce, and has recently been shown to work in this context [69].

Beyond editing the human genome, gene editing approaches can be used to target other organisms and aid in the development of therapeutics. For example, editing of viral genomes has been shown to aid in the process of vaccine development [70], and editing of antibody-producing organisms can aid in production and development of antibody-based therapies [71]-[73].

\section{Technical challenges in genome editing therapies} Therapeutics aimed at editing somatic mutations are already in clinical trials and have the potential to provide cures for many suffering patients [58]. However, many technical, economic, and ethical challenges remain relating to widespread practical implementation of such therapies. Key questions include: Does this therapeutic satisfy an unmet medical need? How accurately are the genome edits being made and how does the risk of inaccuracy weigh against the severity of a particular disease? How can clinicians deliver genome editing therapies safely and effectively? If genome editing therapies are feasible and effective, would it be irresponsible not to use them? In other words, what, if any, are the responsible clinical paths towards implementation?

Accuracy of CRISPR-Cas9 genome editing continues to be a main focus of research aiming to make this technology clinically translatable [56]. Although Cas9 has been shown to perform a significant number of off-target cutting events when attempting to introduce an edit of interest, accuracy has been improved through engineering of the Cas 9 enzyme and development of editing strategies, such as base editing, that eliminate the need for DNA cleavage [74].

Delivery has also presented a major challenge in translating gene therapies to the clinic since the early stages of trials [58], evidenced by the case of Jesse Gelsinger, the first gene therapy-related death. In 1999, Gelsinger, suffering from a mild form of OTC (ornithine transcarbamylase) deficiency, a monogenic disease, took part in a trial using a modified virus to deliver a new copy of the OTC gene that could restore normal liver function. This would abrogate the need for the dietary control and drug regimen that was the standard of care for this disease at the time [75]. However, the viral vector used to deliver the transgene prompted an immune response in Gelsinger, which led to his death [75]-[77]. Though the clinicians conducting the trial were ultimately revealed to have been at fault for continuing the trial long enough for Gelsinger's death to occur despite earlier negative results, and disputedly should not have enrolled Gelsinger in the trial in the first place due to his health status at the time [78], this tragic story presented a setback to gene therapies in the public eye. Though use of viral vectors as delivery agents is promising, the viruses used for gene therapy delivery can unpredictably trigger unwanted and dangerous immune reactions in some patients, as highlighted by this case.

Recently, scientists have turned to adeno-associated viruses ( $A A V s$ ), viruses that are not known to cause diseases in humans but are able to infect human cells [79]. Clinical trials are ongoing for an array of gene therapies using AAVs as delivery vectors. In early 2018 , Luxturna, a gene therapy to treat an inherited retinal disease made by Spark Therapeutics, became the first AAV-based therapy that was approved by the FDA $[77,80]$. AGN-151587, the CRISPR-based drug currently in in vivo clinical trials for Leber's Congenital Amaurosis, is another notable example [81]. Considering such successes, 
AAV remains a promising mode to deliver genome editing therapies and, in fact, is routinely used in research settings to do so in animal models of disease. However, a current limitation to AAVs is the relatively small amount of genetic cargo that can be packaged in an AAV capsid [82], since most proteins used for genome editing are large and cannot always fit within the size constraints. There are also additional hurdles with the delivery efficiency of $A A V$, immune response, and scale-up of production that are being addressed by researchers to assure that it can be a viable and robust delivery option for therapeutics [83].

As a less immunogenic alternative to viral vectors, scientists have used various nanoparticle formulations to successfully deliver CRISPR-Cas9 systems by systemic injection in mice $[60,84,85]$. Though nanoparticles present a promising delivery avenue, a great deal more work is required to find compositions that will prevent cells from simply degrading the cargo and to avoid the particles getting stuck in the liver when delivered systemically instead of effectively reaching the target cells [60].

\section{Ethical concerns in therapeutic genome editing}

Beyond technical challenges, ethical questions remain ever present in the conversation surrounding therapeutic genome editing, both for heritable and somatic edits. These questions must be weighed carefully in order to responsibly balance unmet medical needs with the broader societal implications of using these technologies. As with any technology, ensuring equitable access to the potential benefits remains a critical point of discussion [86]. Governments and regulators must consider: how will socioeconomic status play a role in access to novel genome editing therapeutics? Will this contribute to an ever-widening socioeconomic gap?

Existing gene therapies can cost hundred thousands to millions of dollars over a patient's lifetime [87], limiting practical access to only the select few who can afford them. There are several reasons for this. First, gene therapies can cost billions of dollars to develop and are difficult to bring through clinical trials due to great uncertainty in the outcome. This makes the investment risk in development exceptionally high, a cost that is partially shifted to patients. Additionally, the patient pool is often limited, giving companies a small population from which to sell these products to recoup the huge investment, and given the one-time dose nature of such drugs, this cost is packed into the single treatment event. For example, Glybera (alipogene tiparvovec) is an effective non-CRISPR based gene therapy to treat severe familial lipoprotein lipase deficiency that came with a $\$ 1$ million price tag when marketed in Europe. However, it was taken off the market because prices were so high that the number of patients in need that could afford it were too low to justify continued production $[88,89]$. Finally, patent coverage of various gene therapy technologies often dictates how prices are set due to the involvement of licensing fees.

CRISPR-based gene editing therapies are poised to draw similar prices, as all of the above-mentioned factors that drive up the cost of gene therapies will apply to CRISPR-based therapeutics [90]. In particular, the complex patent and licensing landscape remains a main driver of the economic feasibility of developing CRISPR-based therapies, thus contributing to the cost for patients. High costs will likely limit the pool of possible beneficiaries of such treatments, which in turn could contribute to increasing inequality in opportunity and wealth [91]

However, beyond regulated clinical trials and approved products, is access to CRISPR technologies always a good thing? For example, there have been do-it-yourself (DIY) gene editing materials sold over the internet, where buyers can purchase kits claiming to provide the components needed to self-edit with CRISPR. These kits ranged from offering cosmetic edits to allow for bigger muscles to therapeutic edits to provide a cure to HIV [92]. A small but vocal subset within the community of "biohackers," those who perform DIY biological experiments at home or in community bio labs, create and test these kit materials on themselves and animals $[93,94]$

Though it is not explicitly illegal for people to experiment on themselves, it certainly is illegal to sell CRISPR tools marketed as treatments without FDA approval in the United States [95]. In Europe, at-home experimentation of gene editing even with bacteria, plants and animals, let alone with people, is illegal [96]. Concern around these technologies stem largely from the fact that the genetic code of most organisms is far from fully understood by scientists, so it is unclear what kinds of effects these unsupervised and untested modifications can have. However, experts note that it is difficult to generate enough material to administer an effective dose of a CRISPR-based drug to a person without access to academic or industrial labs, making it unlikely that DIY kits will have much effect, positive or negative, on those who try them.

These unregulated activities also serve to highlight broader questions around informed consent, one of the major objections many experts had when evaluating He Jiankui's experiments [97]. There are many concerns on the nature of informed consent with CRISPR technologies, as the technology is still in its early stages of development and many feel there has not been enough time to observe long-term effects. If patients do not have a reasonably complete understanding of the risks and long-term consequences of a procedure, or if scientists are unable to provide this information, can the patients provide informed consent? Going even further, what is the responsibility of a parent consenting to such a therapy that will affect not only the life of their child, but potentially future generations who are obviously unable to provide consent?

Some of the most pressing ethical concerns regarding gene editing arise when considering the situations in which it could be appropriately administered. As discussed, applications are already in trials that can give rise to potentially life-saving treatments for patients, with many more on the horizon. It is hard to argue that a patient should be denied 
such a treatment if it exists and is proven to be safe and effective. However, the larger question of who draws the line between what is an unmet medical need and an enhancement looms. At what point does a gene therapy lean more towards eugenics [98]? This moral and ethical gray area had been debated for decades, with many worrying about what path these therapies will set society on [99, 100].

For example, there are known mutations in the human genome which are linked to resistance to viruses and bacterial infections such as HIV, norovirus, hepatitis C, malaria and ebola. But would it be acceptable to use germline gene therapies to try and spread these mutations? What about mutations that have more ambiguous societal benefits, such as reduced risk of Alzheimer's, coronary disease, Type 1 and Type 2 diabetes and bipolar disorder? For families with a history of such diseases, making genome edits to reduce disease risk may be an important step in preventative treatment. However, genes involved in risk for such diseases may also have an impact on cognitive function and physical appearance, which may be considered more enhancement than treatment. In either case there are also the ever-present questions of access and affordability with regards to these therapies, if they are ever deemed acceptable to administer.

These morally ambiguous and potentially society-altering questions emphasize the difficulty in designing blanket regulations. However, the fact remains that so many ethical questions on how to move forward with the development of gene editing therapies remain undecided while genome editing technology has become easier than ever before. These technologies could have an existentially transformative impact on humanity, regardless of borders, highlighting a need for both national and international guidelines that can ensure safe progress.

In particular, international agreements on guidelines could aid in addressing the above posed questions on the ethics of gene editing. Given existing wealth disparities between nations, international agreements could serve to ensure equitable access to genome editing medical technologies, despite high costs. Regulations at international level could assist in standardizing the definitions of unmet medical needs versus enhancements as it pertains to gene therapies. Furthermore, international cooperation could prevent the use of patients from disadvantaged populations as test subjects for questionable procedures, which can aid in addressing the need for widespread regulations of informed consent. Finally, international regulation may function to provide guidelines for other potential issues that may arise, such as medical tourism for designer babies or other morally dubious procedures.

These ethical questions have been around for decades and yet have only begun to be explored. Answering them properly will require broad engagement from a variety of stakeholders and voices, including scientists, ethicists, regulators, and, importantly, the general public and those whose lives could be directly impacted by these technologies [101]. This engagement with the public may require educating and providing the tools necessary for the public to be properly caught up to speed on the technology and its projected impacts. Current surveys show that views on genome editing held by the American public depend heavily on the use case [102]. In general, people consider treatment of a serious disease as an acceptable use of gene editing technology, but are less inclined to consider edits made to prevent a baby's risk of developing a serious disease as acceptable. However, interestingly, acceptance of both somatic and germline edits were comparable in the treatment use case [103]. Additionally, a majority of respondents were opposed to genome editing for making enhancements.

Finally, it was found that survey participants with a scientific background or with familiarity of genome editing were more likely to have concrete views towards application of these technologies, either for or against [102,103], underscoring how public engagement and education on this topic may change overall moral consensus on how these technologies should be used. Continuing local, national, and international engagement, education, and survey efforts on a broad scale could allow for more equity in the evaluation process. Though many of these issues will be taken up differently depending on culture, the coalescing of these efforts could lead to regulations that benefit the greater international community, especially those that do not have the scientific or regulatory capacity to develop a framework on their own.

\section{Regulatory frameworks and guidelines}

$\mathrm{He}$ Jiankui's presentation of the first children born with germline editing at the Second International Summit on Human Genome Editing served to highlight the very concerns that were the impetus for forming the summit. The first summit was convened as an international initiative between the U.S. National Academies of Sciences, Engineering, and Medicine and the U.K.'s Royal Society to develop a framework to guide scientists, clinicians, and regulators alike when considering applications of human genome editing [104]. In 2017, the committee published a comprehensive guide on human genome editing, concluding that existing regulatory processes for human gene therapy were sufficient to manage somatic genome editing research, provided that the research was directed towards treating diseases and disabilities, evaluated safety and efficacy for humans within clinical trials, and solicited broad public input on the treatment before leaving the trial phase [105].

On the topic of human germline editing, the committee concluded that research may be permitted in some cases of treatments for serious diseases and disabilities, but that there would need to be extensive oversight to make sure that the technology could be used for other purposes as well as continuous public participation in the process before moving forward. Additionally, they noted that the United States already had a continuing prohibition on funding of research involving intentional modification of human embryos through the FDA [105].

The US prohibition on federally-funded human embryo 
research stems from the Dickey-Wicker Amendment, which has been attached to the appropriations bills for the Departments of Health and Human Services (DHHS) each year since 1996 and prohibits the DHHS, including the National Institutes of Health, from using appropriated funds for research involving human embryos [106]. As mentioned, the FDA also has continuing bans on funding of research involving human embryos [105]. Most recently, in June of 2019, the House of Representatives Appropriations Committee approved a rider to a 2020 bill barring the FDA from approving any clinical trials leading to heritable edits [107]. Somatic gene editing therapies need approval through the DHHS and are regulated through the FDA. In early 2020, the FDA released additional guidance for clinical trials and pathways towards manufacturing these therapies [108].

Other countries around the world are also the process of updating their regulations to cover therapies using somatic gene editing through modifying existing regulations, creating new oversight committees, and releasing recommendations so that clinical trials can be safely approved and conducted. Below we will highlight some of the new and adapted regulations that the international community has adopted in order to improve safety, efficiency, and oversight of gene editing research and therapies. It should be noted that while the countries referenced in the following two paragraphs have supported and encouraged somatic gene editing therapies, they maintain a current regulatory ban on clinical germline gene editing procedures.

The European Union has classified gene therapies as advanced therapy medicinal products (ATMPs), which are regulated by the European Medicines Agency's Committee for Advanced Therapies. Recent updates to its regulations include implementing the Priority Medicine (PRIME) scheme in 2016 to leverage existing EU regulatory tools for expedited ATMP development and clinical trials, as well as a joint action plan between the European Commission and European Medicines Agency in October 2017 focused on improving safety, efficacy, and evaluation of ATMPs and soliciting multi-stakeholder feedback on the challenges involved in developing ATMPs $[109,110]$. The United Kingdom regulates gene therapy trials through the The Medicines for Human Use (Clinical Trials) Regulations 2004, where trials must apply to the Gene Therapy Advisory Committee. The Medicines and Healthcare products Regulatory Agency will assess each application, and will consult with the MHRA Clinical Trials Expert Advisory Group if needed before approval. Though the UK has approved germline genome editing within experimental research, it is illegal to perform germline editing as a therapy.

Australia updated their Gene Technology Regulations in October 2019 to ease restrictions and clarify the approval process for somatic gene therapy clinical trials [111], and requires a licence to perform research on human embryos (though it has yet to grant a license thus far). New Zealand regulates gene therapies under their existing Medicines Act, but has added a Gene Technology Advisory Committee to approve all gene therapies within the country [112]. Israel regulates gene therapies through the Ministry of Health's Genetic Information Law, with additional approval by human research advisory committees and a dedicated advisory committee composed of scientists, ethicists, and physicians. Finally, Brazil released new regulations in 2019 which established gene therapies as a drug and developed a regulatory framework for these therapies to follow.

There are also countries whose regulatory processes and oversight have come into question. China, the first country to approve a gene therapy, has been chastised for the lack of oversight within their research and clinical trials for gene therapies, where trials simply need approval from the ethics committee of the hospital or medical institution where the trial will take place. Issues within the process include inadequate legislation, supervision, checkpoints within the clinical trial process, and care for safety of clinical trial participants $[113,114]$. With regards to germline editing, China has proposed to update their legislation in light of the 2018 CRISPR babies scandal by regulating germline editing research under civil legislation. This legislation falls under personality rights protection and requiring all experiments to be approved through the Ministry of Health [115]

Similarly, Russia currently has no unique regulations for gene editing therapies, with trials and drug approval overseen by the Ministry of Health. The country has ongoing research in germline gene editing, but the Russian Health Ministry claims to support the WHO position against germline editing, stating that gene editing for embryos is premature and that clinical applications should be stalled until there is proof of safety [116]. Japan has also been criticized for their regulations, stemming from the 2014 adoption of an accelerated approval system for regenerative medicines which include gene therapies, along with the Pharmaceuticals, Medical Devices, and Other Therapeutic Products Act (PMD Act), which created a fast-track for clinical trials [117]. Though the country passed a new Clinical Trial Act in 2018, the process has been called into question with regards to gene therapies due to human clinical trials not falling under any legally binding categories [118]. In 2018 the country also approved research involving human embryo editing, though in late 2019 they recommended a ban on implanting the edited embryos [119].

Looking ahead, there are continuing efforts underway to develop a framework that could provide international coordination on the hotly debated scientific and ethical issues surrounding germline gene editing [120]. The National Academy of Sciences, Engineering, and Medicine recently convened a new committee, the International Commission on the Clinical Use of Human Germline Genome Editing, with the goal of developing a comprehensive framework that can be used as a road map from pre-clinical trials through long-term monitoring of the germline-edited patients, acknowledging that the road map will evolve as knowledge on the topic increases [121]. Similar to the recommendations from the 2017 report on human genome editing, the international committee will be 
taking ethical and societal considerations into account when making their recommendations. While this framework is an important start, it does not yet address the need for education and solicitation of a diverse set of voices needed in the global conversation on the development and implementation of these technologies for public use.

The World Health Organization is also seeking to establish oversight and governance mechanisms through convening of a global panel of experts. In July of 2019, the advisory committee issued a statement condemning clinical application of germline genome editing until its implications have been thoroughly considered [122]-[124], effectively recommending a moratorium similar to those previously suggested $[19,23]$. This committee has further recommended development of a global framework using the guiding principles of transparency, inclusivity, fairness, social justice, and responsible scientific stewardship that can be scalable from local to international governments, can work in contexts with both tight and loose regulation of scientific practice, and is developed in collaboration with the widest possible range of stakeholders $[122,124]$. Additional international initiatives have included creation of a global registry to track human genome editing research in both somatic and germline contexts $[125,126]$ in a hope to provide more public transparency to the process of human germline editing research.

\section{Conclusions}

Given the rapid pace of therapeutic developments that make use of gene editing, there are great risks and rewards on the horizon. International frameworks are in development, which will allow for a clearer and smoother journey from research through clinical trials towards approved therapies that can be widely available to those still searching for treatments. There is already significant regulatory infrastructure and guidance on the national level that has been implemented to move somatic gene therapies forward, but germline gene therapies are still highly controversial, even at the research level. Looking towards the future, there is work to be done on safely moving through the pipeline from lab to patient, but more importantly, in increasing the ethical implementation through educating the broader community on gene editing and soliciting engagement from a wide range of voices.

\section{Acknowledgements}

The authors would like to thank Zaneta Matuszek, Ishaan Dev, JoLynn Giancola and Elvira Kinzina for contributions in developing the initial ideas for this piece.

\section{Citation}

Kannan, S. \& Najjar, D. Therapeutic gene editing is here, can regulations keep up? MIT Science Policy Review 1, 64-75 (2020).

\section{Open Access}

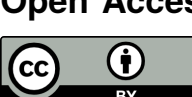

This MIT Science Policy Review article is licensed under a Creative Commons Attribution 4.0 International License, which permits use, sharing, adaptation, distribution and reproduction in any medium or format, as long as you give appropriate credit to the original author(s) and the source, provide a link to the Creative Commons license, and indicate if changes were made. The images or other third party material in this article are included in the article's Creative Commons license, unless indicated otherwise in a credit line to the material. If material is not included in the article's Creative Commons license and your intended use is not permitted by statutory regulation or exceeds the permitted use, you will need to obtain permission directly from the copyright holder. To view a copy of this license, visit http: / / creativecommons.org/licenses / by $/ 4.0 /$.

\section{References}

[1] Cong, L. et al. Multiplex genome engineering using CRISPR/Cas systems. Science 339, 819-823 (2013). https: //doi.org/10.1126/science.1231143.

[2] Mali, P. et al. RNA-guided human genome engineering via Cas9. Science 339, 823-826 (2013). http:// doi.org/10. $1126 /$ science. 1232033 .

[3] Jinek, M. et al. RNA-programmed genome editing in human cells. elife 2 (2013). https://doi.org/10.7554/elife. 00471.

[4] Cho, S. W., Kim, S., Kim, J. M. \& Kim, J.-S. Targeted genome engineering in human cells with the Cas9 RNA-guided endonuclease. Nature Biotechnology 31, 230-232 (2013). https://doi.org/10.1038/nbt.2507.

[5] Hirakawa, M., Krishnakumar, R., Timlin, J., Carney, J. \& Butler, K. Gene editing and CRISPR in the clinic: current and future perspectives. Bioscience Reports 40 (2020). https : // doi. org/10.1042/BSR20200127.

[6] Shahryari, A. et al. Development and clinical translation of approved gene therapy products for genetic disorders. Frontiers in Genetics 10 (2019). https://doi.org/10. 3389/fgene.2019.00868.

[7] Sprink, T., Eriksson, D., Schiemann, J. \& Hartung, F. Regulatory hurdles for genome editing: process-vs. product-based approaches in different regulatory contexts. Plant Cell Reports 35, 1493-1506 (2016). https: //www.ncbi.nlm.nih.gov/ pmc/articles/pmc4903111/.

[8] Dunbar, C. E. et al. Gene therapy comes of age. Science 359 (2018). http://doi.org/10.1126/science.aan4672.

[9] Cohen, I. G., Adashi, E. Y., Gerke, S., Palacios-González, C. \& Ravitsky, V. The regulation of mitochondrial replacement techniques around the world. Annual Review of Genomics and Human Genetics 21 (2020). https://doi.org/10.1146/ annurev-genom-111119-101815.

[10] Krishan, K., Kanchan, T. \& Singh, B. Human genome editing and ethical considerations. Science and Engineering Ethics 22, 597-599 (2016). http://doi.org/10.1007/s11948$015-9675-8$.

[11] Evitt, N. H., Mascharak, S. \& Altman, R. B. Human germline CRISPR-Cas modification: toward a regulatory framework. The American Journal of Bioethics 15, 25-29 (2015). https: // doi.org/10.1080/15265161.2015.1104160.

[12] Cyranoski, D. First CRISPR babies: six questions that remain Nature (2018). https://doi.org/10.1038/d41586-01807607-3.

[13] Regalado, A. Exclusive: Chinese scientists are creating CRISPR babies. In MIT Technology Review (2018). https://www.technologyreview.com/2018/11/ 25/138962/exclusive-chinese-scientists-arecreating-crispr-babies/.

[14] Cyranoski, D. CRISPR-baby scientist fails to satisfy critics. Nature (2018). https://www. nature.com/articles/ d41586-018-07573-w. 
[15] Normile, D. Shock greets claim of CRISPR-edited babies (2018). http://doi.org/10.1126/science.362.6418. 978.

[16] HT, G. He Jiankui, embryo editing, CCR5, the London patient, and jumping to conclusions. STAT (2019). https://www.statnews.com/2019/04/15/jiankuiembryo-editing-ccr $5 /$.

[17] Cyranoski, D. \& Ledford, H. Genome-edited baby claim provokes international outcry. Nature 563, 607-608 (2018). http://doi.org/10.1038/d41586-018-07545-0.

[18] Lanphier, E., Urnov, F., Haecker, S. E., Werner, M. \& Smolenski, J. Don't edit the human germ line. Nature 519, 410-411 (2015). http://doi.org/10.1038/519410a.

[19] Baltimore, D. et al. A prudent path forward for genomic engineering and germline gene modification. Science 348, 36-38 (2015). http://doi.org/10.1126/science. aab1028.

[20] Cyranoski, D. Russian biologist plans more CRISPR-edited babies. Nature (2019). https://www.nature.com/ articles/d41586-019-01770-x.

[21] Cohen, J. Embattled Russian scientist sharpens plans to create gene-edited babies. Science (2019). https: //www.sciencemag.org/news/2019/10/embattledrussian-scientist-sharpens-plans-create-geneedited-babies.

[22] Doudna, J. CRISPR's unwanted anniversary. Science 366, 777 (2019). http://doi.org/10.1126/science.aba1751.

[23] Lander, E. S. et al. Adopt a moratorium on heritable genome editing. Nature 567, 165-168 (2019). https://doi.org/ $10.1038 / d 41586-019-00726-5$.

[24] Baylis, F. \& Darnovsky, M. Scientists disagree about the ethics and governance of human germline editing. In The Hastings Center Bioethics Forum Essay, vol. 17 (2019). https: / /www. thehastingscenter.org/scientistsdisagree-ethics-governance-human-germlinegenome-editing/?s=.

[25] Greely, H. T. CRISPR'd babies: human germline genome editing in the 'He Jiankui affair'. Journal of Law and the Biosciences 6, 111-183 (2019). https://doi.org/10. $1093 / j 1 b / 1 s z 010$.

[26] Charo, R. A. Rogues and regulation of germline editing (2019). http://doi.org/10.1056/NEJMms1817528.

[27] Regalado, A. Rogue Chinese CRISPR scientist cited US report as his green light (2018). https://Www. technologyreview.com/2018/11/27/1821/roguechinese-crispr-scientist-cited-us-report-ashis-green-light/.

[28] Kim, H. \& Kim, J.-S. A guide to genome engineering with programmable nucleases. Nature Reviews Genetics 15, 321-334 (2014). https://doi.org/10.1038/nrg3686.

[29] Choulika, A., Perrin, A., Dujon, B. \& Nicolas, J.-F. Induction of homologous recombination in mammalian chromosomes by using the I-Scel system of Saccharomyces cerevisiae. Molecular and Cellular Biology 15, 1968-1973 (1995). http: //doi .org/10.1128/MCB.15.4.1968.

[30] Cohen-Tannoudji, M. et al. I-Scel-induced gene replacement at a natural locus in embryonic stem cells. Molecular and Cellular Biology 18, 1444-1448 (1998). http: / / doi.org/10.1128/ $\mathrm{MCB} .18 .3 .1444$.

[31] Kim, Y.-G., Cha, J. \& Chandrasegaran, S. Hybrid restriction enzymes: zinc finger fusions to Fok I cleavage domain. Proceedings of the National Academy of Sciences 93, 1156-1160 (1996). https: //doi.org/10.1073/pnas.93. 3.1156.

[32] Bibikova, M. et al. Stimulation of homologous recombination through targeted cleavage by chimeric nucleases. Molecular and Cellular Biology 21, 289-297 (2001). http://doi.org/ $10.1128 / \mathrm{MCB} .21 .1 .289-297.2001$.

[33] Carroll, D. Genome engineering with zinc-finger nucleases.
Genetics 188, 773-782 (2011). https://doi.org/10. 1534 /genetics.111.131433.

[34] Wright, D. A., Li, T., Yang, B. \& Spalding, M. H. TALEN-mediated genome editing: prospects and perspectives. Biochemical Journal 462, 15-24 (2014). https://doi.org/10.1042/BJ20140295.

[35] Christian, M. et al. Targeting DNA double-strand breaks with TAL effector nucleases. Genetics 186, 757-761 (2010). https://doi.org/10.1534/genetics.110.120717.

[36] Joung, J. K. \& Sander, J. D. TALENs: a widely applicable technology for targeted genome editing. Nature Reviews Molecular Cell Biology 14, 49-55 (2012). https : / / doi .org/ $10.1038 / \mathrm{nrm} 3486$.

[37] Barrangou, R. et al. CRISPR provides acquired resistance against viruses in prokaryotes. Science 315, 1709-1712 (2007). http://doi.org/10.1126/science.1138140.

[38] Mojica, F. J., Diez-Villasenor, C., Garcia-Martinez, J. \& Soria, E. Intervening sequences of regularly spaced prokaryotic repeats derive from foreign genetic elements. Journal of Molecular Evolution 60, 174-182 (2005). http://doi.org/10.1007/ s00239-004-0046-3.

[39] Pourcel, C., Salvignol, G. \& Vergnaud, G. CRISPR elements in Yersinia pestis acquire new repeats by preferential uptake of bacteriophage DNA, and provide additional tools for evolutionary studies. Microbiology 151, 653-663 (2005) http://doi.org/10.1099/mic.0.27437-0.

[40] Bolotin, A., Quinquis, B., Sorokin, A. \& Ehrlich, S. D. Clustered regularly interspaced short palindrome repeats (CRISPRs) have spacers of extrachromosomal origin. Microbiology 151 2551-2561 (2005). http://doi.org/10.1099/mic.0. 28048-0.

[41] Horvath, P. \& Barrangou, R. CRISPR/Cas, the immune system of bacteria and archaea. Science 327, 167-170 (2010). http : //doi.org/10.1126/science.1179555.

[42] Brouns, S. J. J. et al. Small CRISPR RNAs guide antiviral defense in prokaryotes. Science 321, 960-964 (2008). https : //doi.org/10.1126/science.1159689.

[43] Garneau, J. E. et al. The CRISPR/Cas bacterial immune system cleaves bacteriophage and plasmid DNA. Nature 468, 67-71 (2010). http://doi.org/10.1038/nature09523.

[44] Chatterjee, P. et al. A Cas9 with PAM recognition for adenine dinucleotides. Nature Communications 11, 1-6 (2020).

[45] Edraki, A. et al. A compact, high-accuracy Cas9 with a dinucleotide PAM for in vivo genome editing. Molecular Cell 73 (2019). http://doi.org/10.1016/j.molcel.2018.12. 003.

[46] Kleinstiver, B. P. et al. Engineered CRISPR-Cas9 nucleases with altered PAM specificities. Nature 523, 481-485 (2015). http://doi.org/10.1038/nature14592.

[47] Nishimasu, H. et al. Engineered CRISPR-Cas9 nuclease with expanded targeting space. Science 361, 1259-1262 (2018). http://doi.org/10.1126/science.aas9129.

[48] Walton, R. T., Christie, K. A., Whittaker, M. N. \& Kleinstiver, B. P. Unconstrained genome targeting with near-PAMless engineered CRISPR-Cas9 variants. Science 368, 290-296 (2020). http://doi.org/10.1126/science.aba8853.

[49] Komor, A. C., Kim, Y. B., Packer, M. S., Zuris, J. A. \& Liu, D. R. Programmable editing of a target base in genomic DNA without double-stranded DNA cleavage. Nature 533, 420-424 (2016). https://doi.org/10.1038/nature17946.

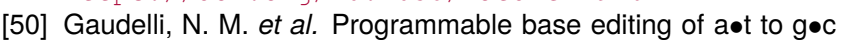
in genomic DNA without DNA cleavage. Nature 551, 464-471 (2017). https://doi.org/10.1038/nature24644.

[51] Abudayyeh, O. O. et al. C2c2 is a single-component programmable RNA-guided RNA-targeting CRISPR effector. Science 353, aaf5573 (2016).

[52] Cox, D. B. et al. RNA editing with CRISPR-Cas13. Science 358, 1019-1027 (2017).

[53] Qi, L. S. et al. Repurposing CRISPR as an RNA-guided platform for sequence-specific control of gene expression. Cell 152, 
1173-1183 (2013). https://doi.org/10.1016/j.cell. 2013.02 .022$.

[54] Perez-Pinera, P. et al. RNA-guided gene activation by CRISPR-Cas9-based transcription factors. Nature Methods 10, 973-976 (2013). http://doi.org/10.1038/nmeth.2600.

[55] Liu, X. S. et al. Editing DNA methylation in the mammalian genome. Cell 167 (2016). http://doi.org/10.1016/j. cell.2016.08.056.

[56] Anzalone, A. V., Koblan, L. W. \& Liu, D. R. Genome editing with CRISPR-Cas nucleases, base editors, transposases and prime editors. Nature Biotechnology 38, 824-844 (2020). http:// doi.org/10.1038/s41587-020-0561-9.

[57] Doudna, J. A. \& Charpentier, E. The new frontier of genome engineering with CRISPR-Cas9. Science 346, 1258096 (2014). http://doi.org/10.1126/science.1258096.

[58] Porteus, M. H. A new class of medicines through DNA editing. New England Journal of Medicine 380, 947-959 (2019). http: //doi.org/10.1056/nejmra1800729.

[59] Zhang, F. Development of CRISPR-Cas systems for genome editing and beyond. Quarterly Reviews of Biophysics 52 (2019). http://doi.org/10.1017/s0033583519000052.

[60] Lino, C. A., Harper, J. C., Carney, J. P. \& Timlin, J. A. Delivering CRISPR: a review of the challenges and approaches. Drug Delivery 25, 1234-1257 (2018). https://doi.org/10. 1080/10717544.2018.1474964.

[61] $\mathrm{Wu}, \mathrm{Y}$. et al. Highly efficient therapeutic gene editing of human hematopoietic stem cells. Nature Medicine 25, 776-783 (2019). https://doi.org/10.1038/s41591-019-0401-y.

[62] Ledford, $H$. Quest to use CRISPR against disease gains ground. Nature 577, 156-156 (2020). https://doi.org/ $10.1038 / d 41586-019-03919-0$.

[63] Ledford, H. CRISPR treatment inserted directly into the body for first time. Nature 579, 185-185 (2020). http: / / doi . org/ $10.1038 / d 41586-020-00655-8$.

[64] Bates, G. Huntingtin aggregation and toxicity in huntingtons disease. The Lancet 361, 1642-1644 (2003). https://doi . org/10.1016/s0140-6736(03)13304-1.

[65] Ekman, F. K. et al. CRISPR-Cas9-mediated genome editing increases lifespan and improves motor deficits in a huntington's disease mouse model. Molecular Therapy - Nucleic Acids 17, 829-839 (2019). https://doi.org/10.1016/j.omtn. 2019.07 .009 .

[66] Carreras, A. et al. In vivo genome and base editing of a human PCSK9 knock-in hypercholesterolemic mouse model. BMC Biology 17 (2019). https://doi.org/10.1186/s12915018-0624-2.

[67] Singh, N., Shi, J., June, C. H. \& Ruella, M. Genome-editing technologies in adoptive $T$ cell immunotherapy for cancer. Current Hematologic Malignancy Reports 12, 522-529 (2017). https://doi.org/10.1007/s11899-017-0417-7.

[68] Eyquem, J. et al. Targeting a CAR to the TRAC locus with CRISPR/Cas9 enhances tumour rejection. Nature 543, 113-117 (2017). https://doi.org/10.1038/ nature21405.

[69] Stadtmauer, E. A. et al. CRISPR-engineered T cells in patients with refractory cancer. Science 367 (2020). http://doi. org/10.1126/science.aba7365.

[70] Okoli, A., Okeke, M., Tryland, M. \& Moens, U. CRISPR/Cas9-advancing orthopoxvirus genome editing for vaccine and vector development. Viruses 10, 50 (2018). https://doi.org/10.3390/v10010050.

[71] Khoshnejad, M. et al. Molecular engineering of antibodies for site-specific covalent conjugation using CRISPR/Cas9. Scientific Reports 8 (2018). https://doi.org/10.1038/ s41598-018-19784-2.

[72] van der Schoot, J. M. S. et al. Functional diversification of hybridoma-produced antibodies by CRISPR/HDR genomic engineering. Science Advances 5, eaaw1822 (2019). https: //doi.org/10.1126/sciadv. aaw1822.
[73] Parola, C., Mason, D. M., Zingg, A., Neumeier, D. \& Reddy, S. T. Genome engineering of hybridomas to generate stable cell lines for antibody expression. In Methods in Molecular Biology, 79-111 (Springer New York, 2018). https:// doi .org/10. 1007/978-1-4939-8730-6_7.

[74] Rees, H. A. \& Liu, D. R. Base editing: precision chemistry on the genome and transcriptome of living cells. Nature Reviews Genetics 19, 770-788 (2018). https://doi .org/10.1038/ s41576-018-0068-0.

[75] Stolberg, S. G. The biotech death of Jesse Gelsinger. The New York Times (1999). https://www. nytimes. com/1999/11/28/magazine/the-biotech-death-ofjesse-gelsinger.html.

[76] Lehrman, S. Virus treatment questioned after gene therapy death. Nature 401, 517-518 (1999). https: / / doi .org/10. $1038 / 43977$

[77] Cross, R. The redemption of James Wilson, gene therapy pioneer. Chemical Engineering News https: //cen.acs.org/business/The-redemption-ofJames-Wilson-gene-therapy-pioneer/97/i36.

[78] Stolberg, S. G. F.D.A. officials fault Penn team in gene therapy death. The New York Times (1999). https://archive.nytimes.com/www.nytimes.com/ library/national/science/health/120999hthgene-therapy.html.

[79] Hastie, E. \& Samulski, R. J. Adeno-associated virus at 50: A golden anniversary of discovery, research, and gene therapy success-a personal perspective. Human Gene Therapy 26, 257-265 (2015). https://doi.org/10.1089/hum.2015. 025.

[80] Food Drug Administration. FDA approves novel gene therapy to treat patients with a rare form of inherited vision loss (2017). https://www. fda.gov/news-events/pressannouncements/fda-approves-novel-gene-therapytreat-patients-rare-form-inherited-visionloss.

[81] Hampton, T. With first CRISPR trials, gene editing moves toward the clinic. JAMA 323, 1537-1539 (2020). http: //doi.org/10.1001/jama.2020.3438.

[82] Wu, Z., Yang, H. \& Colosi, P. Effect of genome size on AAV vector packaging. Molecular Therapy 18, 80-86 (2010). https://doi.org/10.1038/mt.2009.255.

[83] Li, C. \& Samulski, R. J. Engineering adeno-associated virus vectors for gene therapy. Nature Reviews Genetics 1-18 (2020). https://doi.org/10.1038/s41576-019-02054.

[84] Givens, B. E., Naguib, Y. W., Geary, S. M., Devor, E. J. \& Salem, A. K. Nanoparticle-based delivery of CRISPR/Cas9 genome-editing therapeutics. The AAPS Journal 20 (2018). https://doi.org/10.1208/s12248-018-0267-9.

[85] Lee, B. et al. Nanoparticle delivery of CRISPR into the brain rescues a mouse model of fragile $X$ syndrome from exaggerated repetitive behaviours. Nature Biomedical Engineering 2, 497-507 (2018). https://doi.org/10. $1038 / \mathrm{s} 41551-018-0252-8$.

[86] Hildebrandt, C. C. \& Marron, J. M. Justice in CRISPR/cas9 research and clinical applications. AMA Journal of Ethics 20, E826-833 (2018). https://doi.org/10.1001/ amajethics.2018.826.

[87] Irvine, A. Paying for CRISPR cures: The economics of genetic therapies Accessed July 2020, https: //innovativegenomics.org/blog/paying-forcrispr-cures/.

[88] Wilson, R. C. \& Carroll, D. The daunting economics of therapeutic genome editing. The CRISPR Journal 2, 280-284 (2019). http://doi.org/10.1089/crispr.2019.0052.

[89] Sherkow, J. CRISPR, patents, and the public health. Yale Journal of Biology and Medicine 90, 667-672 (2017). https://www.ncbi.nlm.nih.gov/pmc/articles/ PMC5733839/. 
[90] Kozubek, J. Who will pay for CRISPR? (2017). Accessed July 2020, https://www.statnews.com/2017/06/26/ crispr-insurance-companies-pay/.

[91] Isaacson, W. Should the rich be allowed to buy the best genes? (2019). Accessed July 2020, https: //airmail.news/issues/2019-7-27/should-therich-be-allowed-to-buy-the-best-genes.

[92] West, R. M. \& Gronvall, G. K. CRISPR cautions: Biosecurity implications of gene editing. Perspectives in Biology and Medicine 63, 73-92 (2020). http://doi.org/10.1353/ pbm. 2020.0006 .

[93] Zhang, S. A biohacker regrets publicly injecting himself with CRISPR. The Atlantic (2018). https: //www. theatlantic. com/science/archive/2018/02/biohacking-stuntscrispr/553511/.

[94] Addison, C. CRISPR cowboys? genetic self-experimentation and the limits of the person. In Personhood in the Age of Biolegality, 149-166 (Springer, 2020). https://doi.org/ 10.1007/978-3-030-27848-9 9.

[95] CBER. Information about self-administration of gene therapy (2017). https://www.fda.gov/vaccines-bloodbiologics/cellular-gene-therapy-products/ information-about-self-administration-genetherapy.

[96] Cullmann, V. Biohacking CRISPR: Why human DNA isn't computer code (2020). https://150sec.com/ biohacking-crispr-why-human-dna-isnt-justcomputer-code/13626/.

[97] Jonlin, E. C. Informed consent for human embryo genome editing. Stem Cell Reports 14, 530-537 (2020). https: //doi.org/10.1016/j.stemcr.2020.03.010.

[98] Comfort, N. Can we cure genetic diseases without slipping into eugenics? Beyond Bioethics: Toward a New Biopolitics 175 (2018)

[99] Allen, G. E. Is a new eugenics afoot? Science 294, 59-61 (2001).

[100] Friedmann, T. Genetic therapies, human genetic enhancement, and... eugenics? (2019). https://doi.org/10.1038/ s41434-019-0088-1.

[101] Howard, H. C. et al. One small edit for humans, one giant edit for humankind? points and questions to consider for a responsible way forward for gene editing in humans. European Journal of Human Genetics 26, 1-11 (2018). https: // doi. org/10.1038/s41431-017-0024-z.

[102] Funk, C. \& Hefferon, M. Public views of gene editing for babies depend on how it would be used (2020). https://www.pewresearch.org/science/2018/07/ 26/public-views-of-gene-editing-for-babiesdepend-on-how-it-would-be-used/.

[103] Scheufele, D. A. et al. U.S. attitudes on human genome editing. Science 357, 553-554 (2017). http://doi.org/10.1126/ science.aan3708.

[104] Olson, S. (ed.) Second International Summit on Human Genome Editing: Continuing the Global Discussion (National Academies Press, 2019). https://doi.org/10.17226/ 25343.

[105] National Academis of Sciences, E. \& Medicine. Human Genome Editing (National Academies Press, 2017). https: //doi.org/10.17226/24623.

[106] Kearl, M. Dickey-Wicker Amendment, 1996 Accessed March 2020, https://embryo.asu.edu/pages/dickeywicker-amendment-1996.

[107] Kaiser, J. Update: House spending panel restores U.S. ban on gene-edited babies. Science (2019). https: / / doi . org/10. 1126/science.aay1607.

[108] Voelker, R. FDA policies address development of gene therapies. JAMA 323, 817-817 (2020). http://doi.org/ $10.1001 /$ jama.2020.1784.

[109] Detela, G. \& Lodge, A. EU regulatory pathways for ATMPs: standard, accelerated and adaptive pathways to marketing authorisation. Molecular therapy. Methods \& clinical development 13, 205 (2019). http://doi.org/10.1016/ j.omtm.2019.01.010.

[110] Neez, E., Hwang, T. J., Sahoo, S. A. \& Naci, H. European medicines agency's priority medicines scheme at 2 years: An evaluation of clinical studies supporting eligible drugs. Clinical Pharmacology \& Therapeutics 107, 541-552 (2020). http: //doi.org/10.1002/cpt.1669.

[111] Mallapaty, S. Australian gene-editing rules adopt 'middle ground'. Nature (2019). https://doi.org/10.1038/ d41586-019-01282-8.

[112] Everett-Hincks, J. \& Henaghan, M. Gene editing in aotearoa: Legal considerations for policy makers. Victoria U. Wellington $L$. Rev. 50, 515 (2019). https: //doi.org/10.26686/vuwlr. v50i3.5990.

[113] Rana, P. \& Fang, W. Chinese gene-editing experiment loses track of patients, alarming technology's inventors (2018). https://www.wsj.com/articles/chinese-geneediting-experiment-loses-track-of-patientsalarming-technologys-inventors-11545994801.

[114] Wang, Z.-H., Zhou, G.-H., Sun, L.-P. \& Gang, J Challenges in the ethics review process of clinical scientific research projects in China. Journal of International Medical Research 47, 4636-4643 (2019). http://doi.org/10.1177/0300060519863539.

[115] Cyranoski, D. China set to introduce gene-editing regulation following CRISPR-baby furore. Nature (2019). http://doi . org/10.1038/d41586-019-01580-1.

[116] Dobrovidova, O. Calling embryo editing 'premature,' Russian authorities seek to ease fears of a scientist going rogue (2019). https://www.statnews.com/2019/10/16/russiahealth-ministry-calls-human-embryo-editingpremature/.

[117] Akabayashi, A. Letter to the editor: therapeutic misconception and the role of the research ethics committee. Regenerative Medicine 14, 715-717 (2019). https: / / doi .org/10.2217/ rme-2018-0159.

[118] Akabayashi, A., Nakazawa, E. \& Akabayashi, A. Implementation of Japan's first clinical research regulatory law: background, overview, and challenges. In HEC Forum, vol. 31, 283-294 (Springer, 2019). https: //doi.org/10.1007/s10730-019-09379-3.

[119] Cyranoski, D. Japan set to allow gene editing in human embryos. Nature (2018).

[120] Brokowski, C. Do CRISPR germline ethics statements cut it? The CRISPR Journal 1, 115-125 (2018). https: / / doi .org/ $10.1089 /$ crispr.2017.0024.

[121] National Academies of Sciences, E., Medicine et al. International commission on the clinical use of human germline genome editing. Projects \& Activities (2019). https: //www8. nationalacademies.org/pa/projectview.aspx.

[122] World Health Organization. As we explore options for global governance, caution must be our watchword (2019). https://www. who.int/ethics/topics/humangenome-editing/ethics-explore-options-forglobal-governance.pdf?ua=1.

[123] World Health Organization. Statement on governance and oversight of human genome editing (2019). https: //www. who.int/news-room/detail/26-072019-statement-on-governance-and-oversightof-human-genome-editing.

[124] Tuerlings, E. WHO expert advisory committee on developing global standards for governance and oversight of human genome editing: Background paper governance 1: Human genome editing (2019). https://www.who.int/ethics/ topics/human-genome-editing/WHO-CommissionedGovernance-1-paper-March-19.pdf.

[125] Nature Editorial. How to respond to CRISPR babies 564 , 5 (2018). https: //www. nature.com/magazine-assets/ d41586-018-07634-0/d41586-018-07634-0.pdf. 
[126] World Health Organization. WHO launches global registry on human genome editing (2019). https://www. who. int/news-room/detail/29-08-2019-who-launchesglobal-registry-on-human-genome-editing. 